\title{
BREVE NOTÍCIA SOBRE O "KORMTCHAJA KNIGA”.
}

\author{
NIKO ZUZZEK
}

Disciplina: História Bizantina.

\section{INTRODUÇAOO.}

Os códigos de leis são uma das principais fontes históricas. A legislação, considerada como produto da sua época, nos revela as próprias estruturas da sociedade da qual emanou e, por outro lado, considerada como norma, reflete fielmente o esforço consciente por meio do qual o homem tentou plasmar a sua civilização. Conhecer a lei, é conhecer a respectiva época ou civilização. Apesar do lugar comum, a descoberta e a decifração do Código de Hamurabi é a melhor demonstração da nossa afirmação.

$O$ intuito do presente artigo é oferecer ao leitor brasileiro o primeiro contacto com o principal Código do Direito Canônico Russo, frequentemente chamado de Corpus Iuris Canonici da Igreja Russa, o denominado Kormtchaja Kniga. O artigo não pretende tratar do conteudo do Código, mas tenciona explicar seu nome e indicar suas origens.

\section{DO NOME.}

Sobre o nome do Código foram e continuam sendo travadas acirradas discussões. Não há, porem, dúvida quanto ao significado do mesmo.

K'rma ou korma em eslavão, como tambem em russo, significa timão. Kormtchij é timoneiro ou piloto e kormtchaia adjetivo posse-

(1). - Zusek (I.), Kormtchaja Kniga, Studies on the Chief Code of Russian Canon Law, in "Orientalia Christiana Analecta", n' 168, Roma 1964, p. 1 . 
ssivo derivado de kormtchij. Kniga é livro. A tradução literal do título portanto seria $O$ Livro do Timoneiro, a tradução mais livre $O$ Mapa do Piloto e, conforme o sentido mais próprio, a nossa sugestão do título seria " $O$ Livro Piloto" (2).

Esta denominação, um tanto estranha à primeira vista para um código, reveste-se de profundo significado quando considerada dentro do tradicional simbolismo da Igreja representada pelo barco que está atravessando o mar tempestuoso cheio de escolhos perigosos. E exatamente neste sentido que a primeira edição gráfica do Código, feita em 1653, explica o título:

"Como na arte de navegar no mundo (mar) material o fator mais importante para todos os passageiros é a orientação da nave, uma vez que a segurança dos passageiros depende da direção dada por habil piloto, assim tambem no mar (espiritual) deste mundo, na arte de navegar o barco das Divinas Escrituras, o imprescindivel e de suma importância para os passageiros deste barco - a Igreja do Cristo - é a pilotagem, quer dizer o dogma divino dos Santos Apóstolos e Santos Padres dos Sete Concílios Ecumênicos e dos Nove Sínodos Regionais e da Tradição (Eclesiástica) expressa neste livro. Por meio đestes (elementos) em conjunto todos os passageiros do mar desta vida estão sendo instruidos e salvos sob direção dos hábeis pilotos, isto é Pastores e Mestres. Deste modo eles atravessam sem dificuldade os vórtices das paixões espirituais e corporais provocadas e excitadas em nós por maus espíritos e são levados para os tranquilos e bonançosos portos da felicidade eterna da celeste Jerusalém. Pela sua aptidão de alertar-nos dos perigos e de conduzir-nos a compreender o seu próprio conteudo, este (código) foi chamado com propriedade Livro Piloto" (3).

Se não há dúvida quanto ao significado do título, menos clara é a questão das suas origens. Um grupo de estudiosos das fontes do direito canônico russo sustenta que o título é quase cópia do grego. Liderados por Rozenkampf eles afirmam que

(2). - Origens etimológicas dos termos acima podem ser encontradas em: Miklositch (F.), Lexicon palaeoslovenico-graeco-latinum, Viena 1862-1865, dd. 155-156; Preobrashensky (A.G.), Etymological Dictionary of the Russian Language, New Yo.k 1951 (ed. fotostática), pp. 355 e 322. p. 9 .

(3). - Kormtchaja Kniga de 1653, f. 642 ab - apud Zuzek, op. cit. 


\begin{abstract}
"desde tempos remotos as coleções canônicas gregas levavam a denominação de Pedálion (4).
\end{abstract}

Pedalion quer dizer timão, de modo que esta palavra era o ponto de partida para o título russo. Contudo, outro grupo encabeçado por Golubinskij considera a opinião de Rozenkampf um

"erro absurdo" (5),

pois, enquanto já no século XIII alguns códigos russos eram entitulados Kormtchaja Kniga, a denominação grega Pedalion para os códigos gregos só aparece no começo do século XIX sob visivel influência da titulação eslávica (6). A posição de Golubinskij nos parece bastante sólida.

Menos convincente é a explicação do mesmo autor no que concerne as razões linguísticas que teriam induzido os russos a escolher o presente título. A explicação de Golubinskij é a seguinte: o código é a tradução do Nomocanon grego; a tradução literal da denominação Nomocanon é Zakonupravilo ou Zakono-Pravilo, do zakon (nómoslei) e pravilo (canon-regra, normal); deslocando-se na palavra právilo o acento para penúltima sílaba teríamos pravílo, que é o mais próximo sinônimo de korma, que quer dizer timão (7). A maioria dos autores não aceita esta explicação, pois a tradução Lei-Timão, ou sua melhor alternativa, O Timão da Lei, toca os limites do absurdo e ridículo.

Admitindo a origem eslávica do título, não queremos contudo eliminar totalmente a influência grega. De fato, nas orações litúrgicas do Typicon da Igreja da Santa Sofia de Constantinopla, em uso tambem na Rússia no decorrer dos séculos XI-XIV, os Patriarcas são chamados de Theophoroí Kybernêtai laôu (8), expressão traduzida parcialmente em eslavão e aplicada aos bispos como Bogonosnii Kormtchii (Pilotos portadores de Deus) - omitida a tradução do termo laôu (do povo). Não se trata de mera coincidência o fato de ter o mesmo autor, o Arcebispo Clemente de Novgorod ( $\dagger 1299$ ), traduzido uma parte do acima mencionado Typicon e, ao mesmo tempo, conferido pela primeira vez a um código russo o título Kormtchaia Kniga.

(4). - Rozenkampf (G.A.), Obozrenie Kormtchej Knigi v istoritcheskom vide (Recensão da Kormtcaja Kniga do ponto de vista histórico), Moscou 1829, pp. 59 e 68 .

(5). - Golubinski (E.), Istorija Russkoj Tserkvi (História da Igreja Russa), Moscou. 1901-1911 (ed. fotostática), Vol. I, p. 660.

(6). - Ibidem.

(7). - Ibidem.

(8). - Mateos (J.), Le typicon de la Grande Eglise, in "Orientalia Christiana Analecta", no 165, Roma 1962, Vol. I, pp. 66 e 108. 
Dentro do contexto da discussão ainda acesa, nos permitimos aventar uma nova hipótese para solução do problema. Por volta do ano 1274 foi composta uma coleção de leis canônicas russas chamada Merilo Pravednoe (Balança da Justiça), precedida por um prefácio em forma de exortação, de relação bem anterior, endereçada ao GrãoPríncipe de Kiev. Nesta exortação o Príncipe é chamado de Kormtchij (9). Tudo indica que o autor da exortação é o Metropolita Nicéforo (1103-1121) e o príncipe a quem o escrito se dirige é Vladimir Monômaco (1113---24). Ora, os Ruriks, a família reinante na Rússia de Kiev, eram de origem varegue e conservaram por muito tempo seus antigos padrões de governo. Pode ser que o título de Kormtchij ou Piloto, dado ao Grão-Príncipe, seja uma reminiscência dos tempos em que os varegues percorriam os rios russos com suas embarcações sob liderança dos seus hábeis pilotos que, como os Vikings, eram normalmente chefes da equipagem. Kormtchij, então, seria a tradução eslávica para designar a função exercida pelo piloto e, ao mesmo tempo, chefe de uma embarcação varegue. Aplicação posterior deste nome aos príncipes da dinastia varegue não nos parece hipótese fantasiosa.

Juntando os elementos grego e o varegue, os russos tinham razões mais do que suficientes para denominar o seu código com o nome de Kormtchaja Kniga - O Livro Piloto.

Quanto à época do aparecimento do título pela primeira vez não há sérias discrepâncias entre os autores. Há convergência de vários fatores que permitem concluir com certeza que o nome foi usado pela primeira vez em Novgorod no fim do século XIII por volta de 1280 sob o seguinte título: Knigi glagolemya Kormtchii, rekshe pravilo zakonu, greth'kim iazykom Nomocanon (Livro Piloto, denominado tambem norma da lei, em grego Nomocanon) (10).

A partir desta época o nome Kormtchaja Kniga espalhou-se por todos os paises eslavos e é atualmente usado pelos canonistas russos, sérvios e búlgaros para designar o Corpus Iuris Canonici (11).

\section{DA PROCEDENCIA.}

Kormtchaia Kniga é basicamente a tradução e adaptação do Nomocanon grego. Mas que é Nomocanon e qual deles serviu para a tradução?

(9). - Tichomirov (M.V.), Issledovanie o Russkoj Pravde (Pesquisa sobre a "Justiça Russa"). Moscou-Leningrado. 1941, pp. 95-97.

(10). - Golubinski, op. cit., Vol. I, p. 660; Zuzek, op. cit., p. 12.

(11). - Zuzek, op. cit., p. 13. 
Nomocanon pode ser definido como código eclesiástico que reune em si tanto as leis eclesiásticas (cânones), como tambem as leis estatais (nómoi) que dizem respeito aos assuntos da Igreja. No sentido mais amplo da palavra qualquer código eclesiástico que contenha ambas as categorias de leis, pode ser chamado de Nomocanon. No sentido mais restrito, porem, Nomocanon designa somente aqueles códigos onde as leis da Igreja e do Estado se fundem de modo a constituir uma lei básica (12) .

$\mathrm{Na}$ época da cristianização da Rússia estavam em uso na Grécia dois Nomocanones. Um, no sentido mais amplo do termo, de João Escolástico, presbítero antioqueno e depois Patriarca Constantinopolitano (565-578) e outro, no sentido mais restrito da palavra, atribuido a. famoso Patriarca Constantinopolitano Fócio $(857-867 ; 878-880)$ (13).

O Nomocanon de João Escolástico é dividido em duas partes: a primeira é constituida dos cânones dos apóstolos, dos cânones dos primeiros quatro Concílios Ecumênicos, das disposições dos seis sínodos regionais e é dividido em 50 títulos (14).

0 Nomocanon, denominado de Fócio, foi elaborado pela primeira vez por um autor anônimo antes do Concílio em Trullo (692), sofreu uma segunda redação e complementação após o Sétimo Concílio Ecumênico (787), pois as disposições deste Concílio fazem parte da segunda redação. Fócio, por volta do ano 883 atualizou-o e deu-lhe a sua forma definitiva. Pela divisão do conteudo em 14 títulos, o código é tambem denominado "Nomocanon de Quatorze Títulos" (15). Ele é dividido em duas partes: a primeira é composta de cânones eclesiásticos acompanhados por resumos ou, ao menos, indicações da respectiva legislação estatal; a segunda parte é constituida de comentários e interpretação dos cânones contidos na primeira parte (16).

Ambos Nomocanones, o de João Escolástico e o de Fócio, foram traduzidos para o eslavão antes da cristianização da Rússia. Os morávios, os búlgaros e sérvios possuiam estas traduções antes dos russos. Mas qual dos dois códigos foi traduzido em primeiro lugar? Pela lógica devemos admitir que foi o de João Escolástico; por ser

(12). - Golubinskij, op. cit., Vol. I, 642-643; para outra divisão veja Zuzek, op. cit., p. 16 nota 5.

(13). - Apud Golubinski, op. cit., Vol. I. pp. 642-660.

(14). - Trata-se de Synagogé Kanonon ekklesiastikôn eis 50 títlous dieireméne" (Coleção de cánones eclesiásticos denominada de 50 títulos), composta por volta de 550 .

(15). - Clercq, (C. de), Nomocanons of Fourteen Titles, in "Dictionnaire de Droit Canonique", II, 1171-1177.

(16). - Golubinskij, op. cit., Vol. I. p. 645. 
menos completo e menos organizado não teria sentido de traduzi-lo se o fociano fosse traduzido em primeiro lugar.

Quem foi o tradutor? A discussão entre os estudiosos do assunto foi longa, mas atualmente grandes historiadores do mundo eslavo concordam em atribuir a tradução a São Metódio, irmão de São Cirilo, ambos considerados como apóstolos dos eslavos (17). Para que se chegasse a esta conclusão os maiores méritos são devidos a estudos filológicos. Assim, foi confirmada a tradição contida na antiga biografia de São Metódio, na qual se afirma ter o santo traduzido o Nomocanon a pedido do Príncipe Rostislav da Panônia (18). Tudo indica que o local da tradução foi a Morávia, território sob jurisdição arquiepiscopal de Metódio. Os Morávios, apesar de terem sido cristianizados por São Cirilo e São Metódio, não aceitaram o cristianismo em forma oriental, mas ocidental. Por isso a tradução feita por Metódio tinha que ser adaptada aos usos locais. Assim, por exemplo, a palavra grega klerikói é traduzida pelo termo strishniki que significa "tonsurados". Os clérigos ocidentais podiam ser indiscutivelmente chamados com este nome porque a tonsura era de fato o sinal externo do seu estado clerical, mas para os ocidentais, que não permitiam aos clérigos o corte dos cabelos e da barba, a denominação teria sido um contrasenso (19).

Se procurarmos pelas razões da preferência de São Metódio para o Nomocanon de João Escolástico, só podemos responder em forma de suposição. Quando os irmãos, apóstolos dos eslavos, partiram para a sua missão o Nomocanon de Fócio em sua redação e organização definitiva ainda estava sendo elaborado. A brevidade do Nomocanon de João Escolástico tambem era um fator que provavelmente influenciou a escolha do tradutor. Não se tem certeza se São Metódio traduziu somente a primeira parte do Nomocanon, composta de cânones, ou tambem a segunda, composta das respectivas leis estatais. A dúvida surge pelo fato de não possuirmos os manuscritos da tradução da época pré-mongólica e os manuscritos posteriores omitem a segunda parte referente a leis estatais. Contudo, muitos autores opinam que a omissão foi feita posteriormente, quando as leis estatais contidas no Nomocanon de João Escolástico não mais interessavam aos russos e tinham que ser substituidas por outras (20). Se São Metódio traduziu - Nomocanon na sua íntegra com algumas adaptações, a nítida distinção entre os cânones e a lei estatal deste código favorecia tanto a compreensão do conteudo, como a adaptação da lei, especialmente a estatal, a um povo que não era de dependência bizantina .

(17) . - Os mais importantes entre eles são Pavlov, Benechevitch, Vostokov, Golubinskij e Vachitza, apud Zuzek, op. cit., pp. 17-18.

(18). - Zuzek, op. cit., pp. 17-18; vide Dvornik (F.), The Slavs, Boston 1956; Grivec, Konstantin und Method, Lehrer der Slaven, Wiesbaden 1960. (19). - Golubinskij, op. cit., Vol. I. p. 645 nota 708 .

(20). - Idem, p. 64 . 
Da Morávia a tradução metodiana penetrou nas terras dos outros eslavos e no fim na Rússia. $\mathrm{O}$ acervo dos manuscritos com suas numerosas variantes procedente desta tradução é denominado no campo da pesquisa da história do direito russo como Ustiuchkaja Familia (Família de Ustiug) (21).

Tambem a tradução do Nomocanon de Fócio (de Quatorze Títulos), foi introduzida na Rússia antes da invasão mongólica, contudo, não já em sua forma definitiva dada pelo Patriarca Fócio, mas na sua segunda redação feita logo após o Sétimo Concílio Ecumênico. Em relação à redação fociana esta era menos completa e menos organizada.

Ao contrário do caso anterior, a autoria da tradução é desconhecida (22). Alguns autores russos eram de parecer que a tradução diretamente do grego foi feita na própria Rússia. Esta opinião é atualmente categoricamente rejeitada pela maioria dos historiadores russos (23). Tudo indica que os russos receberam-na dos búlgaros. De fato, a Rússia foi cristianizada um século depois da morte de Fócio. Durante este século a redação fociana do Nomocanon sobrepujou a redação anterior que ficou arcaica e superada. Se os neófitos russos tencionassem traduzir o Nomocanon diretamente do grego, eles teriam escolhido um texto considerado atualizado e não de redação mais antiga, como aconteceu. Os Búlgaros, por outro lado, foram cristianizados nos anos 864-865, antes que Fócio retocasse o Nomocanon, de modo que tiveram que servir-se deste na sua segunda redação, aliás, a melhor na época.

$\mathrm{Na}$ primeira parte do Nomocanon de Fócio, conforme já mencionamos, os assuntos são tratados simultaneamente pelas leis canônica e estatal. Ora, na tradução, as leis estatais foram omitidas. Qual a razão desta omissão? No texto grego as respectivas leis estatais acompanhavam os cânones em forma de breves resumos ou, então, eram simplesmente indicadas. Para que pudessem ser compreendidas era preciso recorrer ao Código de Direito Civil de Justiniano, de modo especial às Novelas. Mas a legislação justiniana não foi traduzida, por isso qualquer referência a ela tornou-se inutil. Para suprir a falha o tradutor

(21). - Zuzek, op. cit., pp. 14-20.

(22). - Veja a indicação da discussão sobre o assunto em Zuzek, op. cit., pp. 26-27; cfr. Troickhij (S. V.), Spor Starog Rima sa Novim na stranama slovenske Krmtchije (A disputa da Antiga Roma com a Nova nas páginas do Nomocanon eslavo), ed. pela Academia de Ciências da Sérvia, Livro CCCXXXII, Belgrado 1960; Jugie (M.), Le plus ancien recueil canonique slave et la primauté du pape, in "Bessarione" 34, ano 1918, no 53.

(23). - Pavlov (A.S.), Pervonatchalnij Slavenskij Nomokanon (O p-imordial nomocanon eslávico), Kazan 1869, p. 10 e squ.; Golubinskij, op. cit., Vol. I. pp. 648-649. 
acrescentou ao Nomocanon de Fócio, assim mutilado, trechos da segunda parte do Nomocanon de João Escolástico, constituida das leis estatais que dizem respeito à Igreja (24).

Aś cópias provenientes desta tradução são classificadas e denominadas pelos historiadores russos de Efremovskaia Familia (Família de Efrem) (25).

Após a invasão mongólica a Rússia recebe uma outra tradução do Nomocanon. Em 1274, no sínodo de Vladimir, o Metropolita Cirilo promulgou-a como "Código da Igreja Russa" (26). Perante os bispos reunidos o Metropolita afirmou ter recebido a cópia do Déspota búlgaro Sviatoslav. Baseados nestes dados alguns autores pensavam na origem búlgara da tradução. Contudo, no estado atual da pesquisa histórico-filológica, chegou-se à conclusão que a tradução é obra do primeiro Chefe da Igreja Autocéfala Sérvia, o arcebispo São Sava, filho do Príncipe sérvio Estevão Nemanja, no mundo chamado Rastko. São Sava passou seu tirocínio no Monte Atos, mas em 1219, ano da sua sagração episcopal, conseguiu em Nicéia a autocefalia para a Igreja Sérvia. Na viagem de volta para a pátria, parou em Tessalônica, onde, com intuito de dar desde o começo à sua Igreja diretrizes claras, deu-se ao trabalho de traduzir a Lei Canônica Grega (27).

O que serviu como base à sua tradução? A discussão entre os autores ainda não terminou. Enquanto um grupo sustenta que o tradutor serviu-se do Nomocanon de Fócio, outros declaram esta opinião sem fundamento, afirmando que a obra de Sava é baseada na Synopsis Canonum (28), comentada por Aristenus, que o tradutor teria complementado com inúmeras adaptações e inovações com finalidades de poder governar melhor a sua Igreja. Seria descabido abordar neste breve artigo todas as opiniões a respeito, somente salientamos, que estamos do lado do ilustre professor Ivan Zuzek que na sua obra magistral corsidera

"totalmente errada a afirmação de que a Kormtchaia Kniga de Sava é mera tradução do Nomocanon de Fócio" (29).

(24) . - Golubinskij, op. cit., Vol. I. p. 649. A questão sobre os elementos que entraram a fazer parte desta tradução é bem mais complexa do que faz supọr a explicação de Golubinskij. Não que:emos aqui entrar em discussão, mas preferimos indicá-la em Zuzek, op. cit., pp. 23-28.

(25). - Zuzek, op. cit., pp. 21-28.

(26) . - Pavlov, op. cit., p. 62; Golubinskij, op. cit., Vol. I. pp. 63-64; Ammann (A.M.), Storia della Chiesa Russa, Torino 1948, pp. 50-51.

(27). - Pavlov, op. cit., pp. 62-63.

(28). - Zuzek, op. cit. pp. 34-35.

(29). - Idem, pp. 37-38. 
O Código de Sava penetrou em todos os países eslavos. Sua influência sobre a legislação eclesiástica e estatal foi enorme. Quando a Rússia estava para imprimir pela primeira vez o seu Código de Direito Canônico, após uma seleção prévia, foram consideradas como mais importantes as cópias do Código de Sava, denominadas atualmente em seu conjunto como Riazanskaja Familia (Família de Riazan).

Mas a partir do ano 1280 (ou 1282) a Rússia possui sua própria Kormtchaja Kniga, denominada Russkaja ou Novgorodskaja (de Novgorod). Trata-se do Nomocanon Russo, não somente porque contem vários artigos de origem russa, mas porque foi remanejado integralmente na terra russa e de maneira russa (30). O código foi elaborado por uma comissão sob a presidência do Príncipe Dimitri de Novgorod e o Arcebispo da mesma cidade, Clemente. Para sua composição foi usado o conteudo das traduçōes anteriores: da Efremovskaja Kormtchaja foram tirados os canones, Riazanskaja e Ustiuchkaja forneceram o resto. Tudo foi complementado por elementos tipicamente russos. $D$ código é uma síntese do Direito Canônico Grego, das inovações introzidas por São Sava e das adaptações tipicamente russas.

Da primeira cópia da Família de Riazan (1274) e da primeira cópia da Família de Novgorod (1280) provem todas as coleções posteriores da Lei Canônica Russa até o século XVII (31).

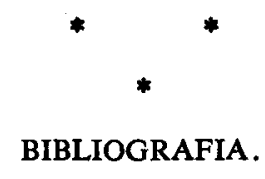

AMMANN (A.M) - Storia della Chiesa Russa, Torino. 1948.

DVORNIK (F.) - The Slavs, Boston. 1960.

GOLUBINSKIJ (E.) - Istorija Russkoj Tserkvi (História da Igreja Russa), Vol. I, Moscou 1901.

GRIVEC - Konstantin und Method, Lehrer der Slaven, Wiesbaden. 1960.

PREOBRASHENSKY (A.G.) - Etymological Dictionary of the Russian Language, New York. 1951.

MATEOS (J.) - Le Typicon de la Grande Eglise, in "Orientalia Christiana Analecta" no 165, Roma. 1962.

MIKLOSITCH (F.) - Lexicon palaeoslovenico-graeco-latinum, Viena. 1862 1865 .

PAVLOV (A.S.) - Pervonatchalnij Slavenskij Nomokanon (O mais antigo Nomocanon eslávico), Kazan. 1869.

(30). - Ammann, op. cit., p. 51 .

(31). - Ibidem. 
JUGIE (M.) - Le plus ancien recueil canonique slave et la primauté du pape, in "Bessarione 34", Roma. 1918.

ROZENKAMPF (G.A.) - Obozrenie Kormtchej Knigi v istoritcheskom vide (Recensão da Kormtchaja Kniga do ponto de vista histórico), Moscou. 1829.

TICHOMIROV (M.V.) - Issledovanie o Russkoj Pravde (Pesquisa sobre a "Justiça Russa"), Moscou-Leningrado. 1941.

TROICKIJ (S.V.) - Spor Starog Rima sa Novim na stranama slovenske Krmtchije (A disputa da Antiga Roma com a Nova nas páginas do Nomocanon eslávico), Belgrado. 1960.

ZUZEK (I.) - Kormthchaja Kniga, Studies on the Chief Code of Russian Canon Law, in "Orientalia Christiana Analecta", Roma 1964.

NIKO ZUZEK. - Nascido em 6 de dezembro de $1925 \mathrm{em}$ Ljubljana, Iugoslávia. Formado pelo Ginásio Clássico Estadual de Ljubljana. Licenciado em Filosofia pela Pontifícia Faculdade de Filosofia de Gallarate (Itália); licenciado em Teologia pela Pontifícia Universidade Gregoriana; especializado em liturgia bizantina, línguas paleoeslava e russa, em problemas ecumênicos pelos Pontifícios Institutos Oriental e Rússico; outros cursos de especialização em St. Beuno's College, St. Asaph, Flintshire, Inglaterra e, Internat St. George, Meudon, França.

Pós-Građuado em História pela Universidade de São Paulo; Doutor em História pela mesma Universidade em 1972 com defesa da tese Razóes da recusa do Gräo-Principado de Moscou a União Florentina. Atualmente professor de História Antiga e ae História Bizantina na Universidade de São Paulo. 